DOI: https://doi.org/10.24144/2409-6857.2018.1(51).298-302

УДК 369.04

Юрченко М.Є., Акименко А.М.

\title{
МОДЕЛЬ ВИЗНАЧЕННЯ ОПТИМАЛЬНОГО ЧАСУ ПОСТАВКИ ПРОДУКЦЇ̈ В УМОВАХ НЕВИЗНАЧЕНОСТІ
}

\begin{abstract}
Постановка и розв'язання задачі стохастичного моделювання управління товарними запасами підприсмства з урахуванням імовірнісного характеру часу виконання замовлення. При побудові математичної моделі в роботі використовується апарат математичного аналізу, теорії оптимізаиії, теорії ймовірностей. Усі стохастичні змінні розглядалися за умови дії закону великих чисел. Встановлено аналітичну залежність, щзо дозволяє визначити оптимальний момент часу поставки товарної продукції з урахуванням мінімізації функції сумарних витрат. Удосконалено математичний апарат пошуку оптимальної стратегії управління запасами з урахуванням імовірнісних параметрів, розподілених за нормальним законом. Використання даної моделі дозволяє ефективно організувати план замовлень і дає можливість знизити торгівельні витрати на підприємстві.
\end{abstract}

Ключові слова: оптимізаційна модель, стохастичні параметри, управління витратами, математична модель.

Постановка проблеми. В умовах загострення конкуренції на споживчих ринках стійкість підприємств забезпечується за допомогою реалізації стратегій, направлених на максимальне задоволення споживчого попиту не тільки на товари, але і на пов'язані з цими процесами послуги, а також на зниження всіх видів торгівельних витрат. Формування таких стратегій визначає необхідність удосконалення різних систем підприємства, у тому числі системи управління товарними запасами на підставах раціоналізації та оптимізації товарних потоків 3 використанням адекватних до постановки цих задач математичних методів i моделей.

Задача управління запасами $є$ на сьогоднішній день однією 3 важливих складових системи логістики. Важливість таких задач призвела до розвитку та удосконалення спеціальних математичних методів, до яких належить теорія масового обслуговування. Відмітимо, що зараз велика увага приділяється дослідженню спеціального класу моделей, які не розглядаються при аналізі систем масового обслуговування, але при цьому істотно впливають на показники ефективності роботи системи в цілому. Особливістю цих моделей $\epsilon$

(C) Юрченко Марина Євгеніївна, кандидат фізикоматематичних наук, доцент кафедри інформаційних систем в економіці, Чернігівський національний технологічний університет, м. Чернігів, тел.: 0509853470, email: marina66@i.ua

Акименко Андрій Миколайович, кандидат фізикоматематичних наук, доцент кафедри інформаційних систем в економіці, Чернігівський національний технологічний університет, м. Чернігів, тел.: 0506468296, email: nakim2@gmail.com розгляд процесу реалізації запасу як випадкового процесу. На сьогоднішній момент більшість практичних задач розв'язано 3 урахуванням детермінованого характеру вхідних параметрів, однак насправді доводиться стикатися 3 ситуаціями, коли вхідні параметри носять стохастичний характер, i застосування класичних методів ускладнено внаслідок труднощів отримання аналітичних співвідношень. 3 цієї причини розробка i вдосконалення математичного апарату стохастичного оптимізаційного моделювання дозволяє уникнути громіздких обчислень і адаптувати модель, що розглядається, до практичних потреб.

Аналіз останніх досліджень і публікацій. Теорія управління запасами $\epsilon$ важливою сферою управлінської діяльності на багатьох підприємствах різних галузей як по виробництву товарів, так і по наданню послуг. Ці питання стають особливо актуальними для раціональної та ефективної організації оптимізації рівня запасів та їх використання, зменшення їх рівня, а також мінімізації оборотних коштів, що вкладені в ці запаси.

Як показано в [1], моделювання процесу управління запасами підприємства передбачає урахування впливу великої кількості параметрів системи і вибір одного 3 багатьох варіантів постановки задачі управління запасами. Відзначимо, що єдина класифікація цих варіантів, незважаючи на численні роботи, реалізована лише частково [2,3]. Деякі автори користуються ітераційними схемами [4], методами апроксимації $[4,5]$, а детальні схеми, алгоритми або програми в дослідженнях практично не наводяться. Детальний аналіз літератури показав, що автори акцентують увагу 
на простих задачах при великій кількості початкових припущень або на більш абстрактну постановку, зневажаючи точними марематичними доказами. Однак розв'язок подібних задач пов'язаний зі значними труднощами обчислювального i математичного характеру, тому подібні методи недостатньо досліджені та оптимальний розв'язок в досліджених моделях отримано не більш ніж у третині випадків.

Незважаючи на спроби створення узагальненої моделі, досліджені на теперішній час в літературі схеми управління запасами можуть бути застосовані до невеликого класу задач, що виникають під час практичної діяльності. Найчастіше керівництво підприємством змушене адаптувати вже існуючі моделі під конкретні умови функціонування.

Як показав аналіз літературних джерел, вибір математичного апарату в значній мірі обумовлений різними характеристиками попиту (витрат продукціï), який може бути або детермінованим, або ймовірнісним.

У свою чергу ймовірнісний попит може бути стаціонарним, при якому функція щільності ймовірності попиту не змінюється 3 часом, або нестаціонарним, при якому функція щільності ймовірності попиту змінюється в залежності від часу. В роботах [5,6] показано, що основними ознаками класифікації моделей управління запасами $є$ попит, параметри управління запасами, обмеження та стратегія управління. Якщо хоча б один з перерахованих параметрів $є$ випадковим, модель стохастична, інакше детермінована.

На сьогодні існують дві базові моделі системи управління запасами: модель 3 фіксованим обсягом замовлення ( $Q$-модель) та модель 3 фіксованим періодом між заказами ( $P$-модель). Однак для названих моделей характерна велика трудомісткість обслуговування i використання, зокрема, $Q$-модель передбачає постійний контроль залишку запасів.

На практиці досить часто виникає невизначеність, що обумовлена неточністю або неповнотою інформації про попит, поставки i інших параметрів логістичної системи. У багатьох випадках вплив випадкових факторів $є$ ключовим, тому при побудові математичної моделі необхідно враховувати випадкові фактори на відміну від детермінованого випадку. Для розв'язання задач 3 невизначеностями авторами [5,6] запропоновані методи теорії множин та імітаційного моделювання. Автором роботи [5] зроблена спроба використати метод інтервального аналізу в системах 3 неповною інформацією про попит, а також представлені числові результати дослідження. Слід зазначити, що характерною особливістю $є$ той факт, що згадані вище автори роблять наголос на пошук розв'язку переважно методами чисельного аналізу. При цьому в більшості постановок для опису випадкових характеристик використовується пуассонівський процес.

Як показано в [6], невизначені фактори можна в свою чергу розділити на стохастичні та повні. Стохастична невизначеність може бути представлена випадковою величиною або випадковим процесом, а повна невизначеність не розглядається як випадковий об'єкт в принципі. Вигляд невизначеності обумовлює вибір математичної моделі.

Формулювання цілей статті. Метою цього дослідження є побудова стохастичної моделі і пошук аналітичного виразу, що дозволяє визначити оптимальний час поставки продукції 3 урахуванням ймовірнісного характеру часу виконання замовлення.

Опис методики проведення дослідження. У роботі для побудови стохастичної моделі 3 невизначеним часом виконання замовлення та детермінованим попитом використовуються методи математичного аналізу, фінансового аналізу, теорії оптимізації, математичного програмування, теорії ймовірностей, методи оптимізаційного та імітаційного моделювання. Детермінованість попиту пояснюється дією закону великих чисел.

Виділення невирішених раніше частин загальної проблеми. На сьогоднішній момент більшість практичних задач 3 цього напряму розв'язано 3 урахуванням детермінованого характеру вхідних параметрів. Низкою авторів для розв'язання зазначеного класу задач застосовуються методи математичного моделювання, теорії масового обслуговування, оптимального управління, однак підсумкові результати не отримали широкого застосування внаслідок складності інтерпретації отриманих аналітичних співвідношень. На практиці доводиться стикатися 3 ситуаціями, коли ряд параметрів носить стохастичний характер, i застосування класичних методів ускладнено через труднощі обчислювального характеру. Отже, подальша розробка оптимізаційних стохастичних моделей управління запасами i отримання саме аналітичного рішення даного класу задач дозволить на практиці підвищити ефективність управлінських рішень.

Опис основного матеріалу дослідження. Будемо розглядати стохастичну модель 3 невизначеністю по часу виконання замовлення $t$, яка є основним фактором виникнення витрат при 
управління запасами. Задача полягає в тому, щоб значно зменшити вплив невизначеності $t$ на виконання нового замовлення. Вважаємо, що попит $P$ в даній моделі детермінований, що в значній мірі пояснюється дією закону великих чисел. Припускаємо, що зі статистичних даних відомий момент закінчення товару $\beta$ в обсязі $V$. При побудові моделі будемо вважати, що існують деякі відмінні від нуля ймовірнісні затримки або передчасне отримання замовленого товару.

Позначимо $y-$ момент реального надходження товару, тому

$$
y=t_{0}+\delta t
$$

де $t_{0}-$ момент призначення отримання замовлення, $\delta t$ - випадкова величина, що характеризує момент відхилення реального часу поставки від того, що планувався. Вважаємо, що випадкова величина $\delta t$ має нормальний розподіл 3 математичним сподіванням $M=0$ та середнім квадратичним відхиленням $\sigma>0$. Відповідно час реального надходження замовлення $y$ також має нормальний розподіл. Це припущення $\epsilon$ необхідною умовою для проведення аналітичних досліджень моделі та в силу особливостей закону нормального розподілу відображає більшість практичних ситуацій.

Вважаємо, що функція витрат $Z$ враховує витрати на зберігання, що розглядаються як втрачена вигода. Витрати зберігання товару в обсязі $V$ після поставки на інтервалі часу до моменту реального закінчення товару $\beta$ у випадку, коли поставка товару відбулася раніше запланованого часу $y(y<\beta)$ складають:

$$
C=\gamma V(\beta-y) \text {, }
$$

де $\gamma=$ const - вартість зберігання одиниці продукції на добу.

При неповному задоволенні попиту $y>\beta$ виникають витрати дефіциту товару на проміжку часу від моменту реального закінчення товару $\beta$ до моменту поставки у в обсязі $V$ :

$$
S=\frac{V}{\beta} \theta(y-\beta),
$$

де $\theta=$ const - прибуток, отриманий від продажу одиниці продукції, коефіцієнт $\frac{V}{\beta}$ характеризує обсяг товару, що був проданий протягом доби.

3 урахуванням (2) і (3), загальні витрати можна представити у наступному вигляді:

$$
C+S= \begin{cases}V \gamma(\beta-y), & \beta>y \\ \frac{V}{\beta} \theta(y-\beta), & y>\beta^{\prime}\end{cases}
$$

Як показано в [6], у якості функції сумарних витрат, що $\epsilon$ випадковою величиною, можна розглядати іiі математичне сподівання, яке в моделі, що розглядається, має наступний вигляд:

$$
F\left(t_{0}\right)=\int_{-\infty}^{\beta-t_{0}} \gamma V\left(\beta-t_{0}-\delta t\right) \mu(\delta t) d(\delta t)+\int_{\beta-t_{0}}^{\infty} \frac{V}{\beta} \theta\left(t_{0}+\delta t-\beta\right) \mu(\delta t) d(\delta t),
$$

де $\mu(\delta t)$ - щільність розподілу неперервної випадкової величини $\delta t$, що характеризує відхилення від терміну поставки.

Представлена задача в $M_{\text {-постановці }}$ зводиться до знаходження такого моменту призначення поставки $t_{0}$, при якому математичне сподівання сумарних витрат буде мінімальним, тобто:

$$
F\left(t_{0}\right) \rightarrow \min .
$$

Зробивши перетворення першого доданку виразу (5), отримуємо

$$
\begin{gathered}
F_{1}\left(t_{0}\right)=\int_{-\infty}^{\beta-t_{0}} \gamma V\left(\beta-t_{0}-\delta t\right) \mu(\delta t) d(\delta t)= \\
=\int_{-\infty-t_{0}}^{\beta-t_{0}} \gamma V \beta \mu(\delta t) d(\delta t)-\int_{-\infty}^{\beta-t_{0}} \gamma V t_{0} \mu(\delta t) d(\delta t)-\int_{-\infty}^{\beta-t_{0}} \gamma V \delta t_{0} \mu(\delta t) d(\delta t) \\
=\gamma V \beta \int_{-\infty}^{\beta-t_{0}} \mu(\delta t) d(\delta t)-\gamma V t_{0} \int_{-\infty}^{\beta} \mu(\delta t) d(\delta t)-\gamma V \int_{-\infty}^{\beta-t_{0}} \delta t^{-\infty} \mu(\delta t) d(\delta t) \\
F_{1}\left(t_{0}\right)=\gamma V \beta \Phi\left(\frac{\beta-t_{0}}{\sigma}\right)-\gamma V t_{0} \Phi\left(\frac{\beta-t_{0}}{\sigma}\right)-\gamma V \int_{-\infty} \delta(\delta t) d(\delta t),
\end{gathered}
$$


разподілу.

Застосовуючи метод інтегрування частинами до третього доданку виразу (7), отримуємо:

$$
\begin{gathered}
\gamma V \int_{-\infty}^{\beta-t_{0}} \delta t \mu(\delta t) d(\delta t)= \\
=\gamma V\left[\delta t \int_{-\infty}^{\beta-t_{0}} \mu(\delta t) d(\delta t)-\int_{-\infty}^{\beta-t_{0}}\left(\int_{-\infty} \mu(\delta t) d(\delta t)\right) d(\delta t)\right]= \\
=\gamma V\left(\frac{\beta-t_{0}}{\sigma}\right) \cdot \Phi\left(\frac{\beta-t_{0}}{\sigma}\right)-\gamma V \int_{-\infty}^{\beta-t_{0}} \Phi(\delta t) d(\delta t)
\end{gathered}
$$

Враховуючи (9), запишемо вираз (8) в наступному вигляді:

$$
\begin{gathered}
F_{1}\left(t_{0}\right)=\gamma V \beta \Phi\left(\frac{\beta-t_{0}}{\sigma}\right)-\gamma V t_{0} \Phi\left(\frac{\beta-t_{0}}{\sigma}\right)-\gamma V\left(\frac{\beta-t_{0}}{\sigma}\right) \Phi\left(\frac{\beta-t_{0}}{\sigma}\right)+ \\
\gamma V \int_{-\infty} \Phi(\delta t) d(\delta t)
\end{gathered}
$$

Аналогічно, перетворюючи другий доданок (5), отримаємо:

$$
\begin{gathered}
F_{2}\left(t_{0}\right)=\frac{V}{\beta} \theta t_{0}\left(1-\Phi\left(\frac{\beta-t_{0}}{\sigma}\right)\right)+\frac{V}{\beta} \theta \int_{\beta-t_{n}}^{\infty} \delta t \mu(\delta t) d(\delta t)- \\
\frac{V}{\beta} \theta\left(1-\Phi\left(\frac{\beta-t_{0}}{\sigma}\right)\right),
\end{gathered}
$$

Зробивши перетворення інтегралу $\int_{\beta-t_{n}}^{\infty} \frac{V}{\beta} \theta \delta t \mu(\delta t) d(\delta t)$, що входить до формули (11), одержуємо

$$
\int_{\beta-t_{n}}^{\infty} \frac{V}{\beta} \theta \delta t \mu(\delta t) d(\delta t)=\frac{V}{\beta} \theta\left(1-\Phi\left(\frac{\beta-t_{0}}{\sigma}\right)\right)-\int_{\beta-t_{n}}^{\infty} \Phi(\delta t) d(\delta t)
$$

Відповідно, з урахуванням (12) вираз (5) для загального інтегралу може бути представлений у вигляді:

$$
\begin{gathered}
F\left(t_{0}\right)=F_{1}\left(t_{0}\right)+F_{2}\left(t_{0}\right)= \\
\gamma V \beta \Phi\left(\frac{\alpha-t_{0}}{\sigma}\right)-\gamma V t_{0} \Phi\left(\frac{\beta-t_{0}}{\sigma}\right)-\gamma V\left(\frac{\beta-t_{0}}{\sigma}\right) \Phi\left(\frac{\beta-t_{0}}{\sigma}\right)+ \\
+\gamma V \int_{-\infty}^{\sigma-t_{0}} \Phi(\delta t) d \delta t+\frac{V}{\beta} \theta t_{0}\left(1-\Phi\left(\frac{\beta-t_{0}}{\sigma}\right)\right)+ \\
+\frac{V}{\beta} \theta\left[\left(1-\left(\frac{\beta-t_{0}}{\sigma}\right) \Phi\left(\frac{\beta-t_{0}}{\sigma}\right)\right)-\int_{\beta-t_{0}}^{\infty} \Phi(\delta t) d \delta t\right]-\frac{V}{\beta} \theta \beta\left(1-\Phi\left(\frac{\beta-t_{0}}{\sigma}\right)\right) .
\end{gathered}
$$

Після перетворень, попередній вираз представимо у вигляді:

$$
F\left(t_{0}\right)=\gamma V \int_{-\infty}^{\beta-t_{0}} \Phi(\delta t) d(\delta t)+\frac{V}{\beta} \theta t_{0}+\frac{V}{\beta} \theta-\frac{V}{\beta} \theta \int_{\beta-t_{0}}^{\infty} \Phi(\delta t) d(\delta t) .
$$

Знаходячи
$F^{\prime}\left(t_{0}\right)=\gamma V\left(-\Phi\left(\frac{\beta-t_{0}}{\sigma}\right)\right)+\frac{V}{\beta} \theta+\frac{V}{\beta} \theta\left(-\Phi\left(\frac{\beta-t_{0}}{\sigma}\right)\right) \quad$ тохідну прирівнюючи її до нуля, отримаємо момент часу, при якому виконується умова мінімуму (6):

$$
t_{0}=\beta-\sigma \Phi^{-1}\left(\frac{\theta}{\gamma \beta+\theta}\right),
$$

де $\Phi(x)$ - нормальна функція розподілу, $\beta$ момент закінчення товару, $\gamma-$ вартість збереження одиниці продукції, $\theta$ - ціна продажу одиниці товару.

3 формули (14) випливає, що оптимальний момент $t_{0}$ визначається параметром $\beta$, а також залежить від параметрів нормального розподілу випадкової величини $\delta t$, що визначають величину відхилення від призначеного терміну поставки нової партії товару.

У таблиці 1 обчислено $t_{0}$ при різних $\gamma$ для значень $\theta=1000$ у.0., $\theta=500$ у.о., $\beta=10$ доб., $M=0, \sigma=1$.

Таблиця 1

Залежність оптимального моменту поставки від вартості зберігання*

\begin{tabular}{|c|c|c|c|c|c|c|c|c|c|c|}
\hline$\gamma$ & 5 & 10 & 15 & 20 & 25 & 30 & 35 & 40 & 45 & 50 \\
\hline$t_{0}$ & 8.332 & 8.665 & 8.876 & 9.032 & 9.158 & 9.264 & 9.354 & 9.434 & 9.505 & 9.569 \\
\hline
\end{tabular}

* Розраховано авторами

Відповідно, на рис.1 надано графічну залежність. Слід зауважити, що з рис. 1 видно, що отримана модель має природну властивість: чим більшим є прибуток від продажу одиниці продукції, тим швидше потрібно здійснювати поставку нової партії. 
Цю особливість легко бачити з формули (14): ясно, що $\frac{\theta}{\gamma \beta+\theta}=1-\frac{\gamma \beta}{\gamma \beta+\theta}$, (15) зростає за $\theta$, відповідно, оскільки пробіт-функція $\Phi^{-1}(\cdot) \epsilon$ зростаючою, (14) спадає за $\theta$.

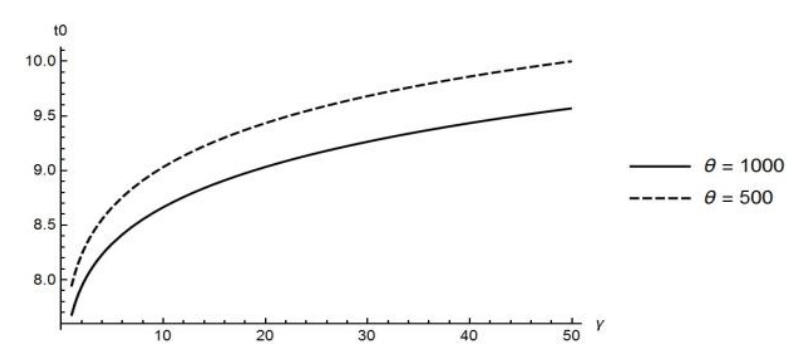

Рис. 1. Графік залежності оптимального моменту поставки від вартості зберігання одиниці продукції*

* Розроблено авторами

Висновки i перспективи подальших досліджень. Представлена нами математична модель дає можливість визначити день доставки нової партії певної кількості товару при відомому попиті та відомих числових характеристиках випадкової величини часу доставки.

Отриманий аналітичний вираз для оптимального часу дозволяе мінімізувати очікувані сумарні витрати на зберігання товару. На відміну від традиційних моделей, вдалося врахувати стохастичний характер часу поставки продукції в умовах імовірнісного характеру часу виконання замовлення.

Наступним кроком може стати відмова від умови нормальності похибки. За допомогою методів непараметричної статистики можливо отримати якісну оцінку функції розподілу цієї випадкової величини; таким чином при використанні саме цієї оцінки стохастичні елементи моделі будуть більш адекватними до реальних задач.

Задача такого роду є актуальною практичною задачею. Її розв'язання дозволяє збільшити ефективність управлінських рішень при виконанні функції керівництва підприємствами що відносяться до будь-яких економічних галузей.

\section{ПЕРЕЛІК ВИКОРИСТАНИХ ДЖЕРЕЛ}

1. Бродецкий Г. Л. Методы стохастической оптимизации / Г. Л. Бродецкий. - М.: РЭА, 2004. - 324 с.

2. Kopytov, E. Modelling of two strategies in inventory control system with random lead time and demand / E.Kopytov, L.Greenglaz, A.Muravyov, E.Puzinkevich // Computer Modelling and New Technologies. - 2007. - Vol. 1 №. 1. - P. 21-30.

3. Шрайбфедер Д. Эффективное управление запасами / Д. Шрайбфедер. - М.: Альпина Бизнес Букс, 2006. $304 \mathrm{c}$.

4. Aggoun, L. On a stochastic inventory model with deteriorating items / L. Aggoun, L. Benkherouf, L. Tadj // IJMMS. - 2001. - V. 25. - № 3. - P. 197-203.

5. Chang, C-T. Optimal ordering policies for deteriorating items using a discounted cash-flow analysis when a trade credit is limited to order quantity / C-T. Chang, L-Y. Ouyang, J-T. Teng, M-C. Cheng // Computers \& Industrial Engineering. - 2010. - Vol. 59. - P. 770- 777.

6. Hung, K.C. Continuous review inventory models under time value of money and crashable lead time consideration / K.C. Hung // Yugoslav Journal of Operations Research. - 2011. - Vol. 21, No. 2. - P.293-306.

\section{REFERENCES}

1. Brodetskiy, G.L. (2004). Metody stokhasticheskoy optimizatsii [Methods of stochastic optimization]. Moscow: REA [in Russian].

2. Kopytov, E., Greenglaz, L., Muravyov, L., Puzinkevich, E. (2007). Modelling of two strategies in inventory control system with random lead time and demand. Computer Modelling and New Technologies, 1, 21-30 [in English].

3. Schreibfeder, D. (2006). Effektivnoe upravlenie zapasami [Effective inventory management]. Moscow: Alpina Business [in Russian].

4. Aggoun, L. (2001). On a stochastic inventory model with deteriorating items. IJMMS, 25(3), 197-203 [in English].

5. Chang, C.-T., Ouyang, L.-Y., Teng, J.-T., Cheng, M.-C. (2010). Optimal ordering policies for deteriorating items using a discounted cash-flow analysis when a trade credit is limited to order quantity. Computers \& Industrial Engineering, 59, 770-777 [in English].

6. Hung, K.C. (2011). Continuous review inventory models under time value of money and crashable lead time consideration. Yugoslav Journal of Operations Research, 21(2), 293-306 [in English]. 